\title{
Development and Characterization of Fast Dissolving Oral Films of Orciprenaline Sulphate
}

\author{
Saili Mahadev Prabhudessai, Panchaxari Mallappa Dandagi, Yashaswini Lakshman* and Anand \\ Panchakshari Gadad
}

Department of Pharmaceutics, KLEU's College of Pharmacy, Belagavi-590010, Karnataka, INDIA.

\begin{abstract}
Introduction: From past few decades there has been a massive change in designing various drug delivery systems to achieve rapid onset of action to treat sudden surprising disorders like hypertensive reactions. Fast dissolving oral films enhance the efficacy of APls by dissolving within a minute in oral cavity after the contact with less saliva without chewing and need of water for administration. Orciprenaline Sulfate belongs to the category of bronchodilators, beta-adrenergic agonist. It is very essential that the drug is released rapidly and hence fast dissolving oral films were designed. Objective: Present study was undertaken with a view of enhancing the bioavailability and to achieve a rapid onset of action as well as to provide better patient compliance especially in pediatric and geriatric patients. Method: The accurately weighed quantity of polymers was kept for soaking overnight in a beaker containing $10 \mathrm{ml}$ of distilled water. The polymeric solution was then stirred for 2 hrs on a magnetic stirrer; Propylene glycol was used as the plasticizer in the concentration of $10 \% \mathrm{w} / \mathrm{w}$ of the polymer concentration. In another beaker weighed quantities of citric acid \& sodium saccharine were added and dissolved in sufficient quantity of distilled water and was stirred for another $30 \mathrm{~min}$ on a magnetic stirrer. Then the polymeric solution and the drug solution with other excipients was mixed together to get a homogenous solution. Further the solution was casted on the glycerine lubricated petridish and was kept for sweltering in an oven at $700 \mathrm{C}$. Results: The surface $\mathrm{pH}$ of all the formulations F1 to F8 was found to be neutral in the range of 6.47-6.82 concluding that films might not cause any potential irritation to the mucosa. All the films showed good disintegration time. Formulation F1 showed the least disintegration time compared to other films. The percentage drug content of all the formulations was found to be in the acceptable range of 94.3-97.9 percent. In vitro drug release study showed that all the films released more than 70 percent of drug within $15 \mathrm{~min}$. From all the formulations F1 containing HPMC E15 as the film forming polymer showed the highest and the best drug release of 98.4 percent within 15 minutes. Conclusion: The results obtained after formulation oral fast dissolving films of Orciprenaline sulfate clearly indicate that it has improved bioavailability and rapid release rate. The formulation is tested for stability and the results are positive hence the formulation is stable.

Key words: Orciprenaline sulphate, HPMC E15, HPMC E50, Fast-dissolving oral films, drug permeated.
\end{abstract}

\section{INTRODUCTION}

Orciprenaline Sulphate is a beta adrenergic agonist (bronchodilator) used in treatment of asthma. This drug is known to undergo high first pass metabolism leading to low bioavailability. Formulation of fast dissolving film of Orciprenaline sulfate has been done with a view of enhancing bioavailability of the drug in order to provide quick onset of action\& to overcome related drawbacks.
For the past few decades there has been a massive change in designing various drug delivery systems to achieve rapid onset of action in order to treat sudden appearing disorders like hypertensive reactions. Fast dissolving films enhance the efficacy of active pharmaceutical ingredients by dissolving in the oral cavity within a minute after the contact with saliva. The
Submission Date: 18-01-2017; Revision Date: 10-04-2017; Accepted Date: 13-07-2017

DOI: 10.5530/ijper.51.4.82 Correspondence: Yashaswini Lakshman, Department of Pharmaceutics, KLEU's College of Pharmacy, Belagavi-590010, Karnataka, INDIA. Mobile no- 9663771158 E-mail: yashaswini.lakshman@gmail.com

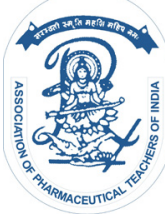

www.ijper.org 
crucial factor is bioavailability of the active ingredient that significantly increases as compared to the conventional tablet dosage forms bypassing first pass metabolism. It also resists the friable nature when compared to dispersible tablets. Orciprenaline Sulfate belongs to the category of bronchodilators, beta-adrenergic agonist. Itis freely solublein waterand is exclusively used in thetreatment of bronchospasm. Itundergoeshigh firstpass metabolism. It has a half life of $6 \mathrm{~h}$ having bioavailability of $40 \%$ (orally) and 3\% (inhaled). Present study was undertaken with a view of enhancing the bioavailability and to achieve a rapid onset of action as well as to provide better patient compliance especially in pediatric and geriatric patients.

\section{Materials}

Orciprenaline Sulfate was obtained as a gift sample from Zydus Healthcare Goa. HPMC E15 and HPMC E50 were also procured as gift samples from Colorcon Pvt. Ltd., Verna Goa. Propylene glycol was obtained as a gift sample from SD Fine Chemicals Pvt. Ltd. Mumbai. All chemicals and reagents were of analytical and pharmaceutical grade.

\section{METHODS}

\section{Formulation of Orciprenaline sulfate loaded oral films ${ }^{2-15}$}

The accurately weighed quantities of polymers were kept for soaking overnight in a beaker containing $10 \mathrm{ml}$ of distilled water. The polymeric solution was then stirred for $2 \mathrm{hr}$ on a magnetic stirrer to obtain a homogenous solution. Propylene glycol was used as the plasticizer in the concentration of $10 \% \mathrm{w} / \mathrm{w}$ of the polymer concentration. It was added to the polymeric solution with continuous stirring. In another beaker, weighed quantities of citric acid \& sodium saccharine were added and dissolved in sufficient quantity of distilled water. The above mixture was stirred for $30 \mathrm{~m}$ on a magnetic stirrer. The polymeric solution and the drug solution with other excipients were mixed together to get a homogenous solution.

The solution was then continuously stirred for $4 \mathrm{hr}$. After mixing of solution, it was set aside for removal of air bubbles and further the solution was casted on the glycerine lubricated petridish and was kept for frying in an oven at $70^{\circ}$. The films were carefully removed after drying and cut into $2 \times 2 \mathrm{~cm}^{2}$ size. Films with any sort of imperfections or defects were ward off from further evaluation. The good quality samples of films were wrapped in a butter paper followed by aluminium foil and stored properly until used.

\section{Evaluation of fast dissolving oral films $\mathrm{s}^{3-7}$}

\section{Physical appearance and surface morphology}

This parameter was investigated by visual inspection of films and by scanning electron microscopy. The samples were mounted on SEM sample slab using a doublesided adhesive tape. The samples mounted were coated with gold $(200 \AA)$ under reduced pressure (0.001 Torr) for $5 \mathrm{~min}$ to improve the conductivity using an Ion sputtering device (JEOL, JFC-1100E, and Japan).

\section{Weight of the film ${ }^{1}$}

The weight of the film was measured by cutting $2 \times 2 \mathrm{~cm}^{2}$ size of the film at 3 different places from the casted film and was weighed on analytical balance and average weight was calculated.

\section{Thickness of the film}

Vernier Calliper was used to measure the thickness of the film. The thickness was measured at three different spots of the film and average was taken and standard deviation was calculated. This is necessary to ascertain uniformity in the thickness of the film as this is directly related to the accuracy of dose in the films.

\section{Folding endurance of the film ${ }^{6,8,11}$}

Folding endurance was determined by repeatedly folding the film $\left(2 \times 2 \mathrm{~cm}^{2}\right)$ at the same place until the film breaks. The number of the times the filmsis folded without breaking was computed as the folding endurance value.

\section{Surface $\mathrm{pH}^{6,9,10}$}

The surface $\mathrm{pH}$ of fast dissolving film was determined in order to investigate the possibility of any side effect in vivo. As an acidic or alkaline $\mathrm{pH}$ may cause irritation of the oral mucosa, the films were made slightly wet with the help of water. The $\mathrm{pH}$ was measured by bringing the electrode in contact with the surface of the film. The method was performed in triplicate and the average with standard deviation was reported.

\section{Swelling Index}

The prepared film sample was weighed and placed on a pre-weighed stainless steel wire mesh. The wire mesh was then submerged in a Petri dish containing $20 \mathrm{ml}$ distilled water. Increase in weight of the film was determined at regular time intervals until a constant weight was obtained and was calculated as difference between the final weight and the initial weight of the film divided by the initial weight. 


\section{Tensile strength}

Tensile strength is the ability of the film to withstand a pulling force. It is calculated by the applied load at rupture divided by the cross-section area of the film in $\mathrm{g} / \mathrm{cm}^{2}$. The film was held between two clamps wherein the upper clamp was fixed and the lower is variable. The force of tearing and elongation was determined.

\section{Percentage elongation}

Percentage elongation is the maximum stress applied to a point at which the film specimen breaks. It is calculated by increase in the length of the film divided by the original length of the film.

\section{Drug content of films}

The films of $2 \times 2 \mathrm{~cm}^{2}$ from three different places from the casted films were taken and individually dissolved in a beaker containing $50 \mathrm{ml}$ of phosphate buffer $\mathrm{pH} 6.8$ using magnetic stirrer. Whatman filter paper was used to filter the solution and was later diluted. After suitable dilutions absorbance was measured at $279 \mathrm{~nm}$ and the drug content was estimated from calibration curve.

\section{In vitro disintegration study ${ }^{9}$}

In vitro disintegration time was determined visually in the petridish containing $20 \mathrm{ml}$ of phosphate buffer having $\mathrm{pH} 6.8$ with swirling every $10 \mathrm{sec}$. The disintegration time is the time when the film starts to dissolve. Disintegration time provides an indication about the disintegration characteristics and dissolution characteristics of the film. Time taken by the film to disintegrate was measured as in vitro disintegration time.

\section{In vitro dissolution study ${ }^{12}$}

In vitro drug release studies of OrciprenalineSulphate fast dissolving oral films were conducted using USP type I (basket type) dissolution test apparatus containing $300 \mathrm{ml}$ of phosphate buffer having $\mathrm{pH} 6.8$ as dissolution medium. The stirrer speed was adjusted to rotate at $50 \mathrm{rpm}$. The temperature of dissolution medium was maintained at $37 \pm 0.5^{0}$ throughout the experiment. The film specimens were placed in a steel basket made up of wire mesh. The film sample in the basket was immersed into the dissolution medium. Samples $(1 \mathrm{ml})$ were withdrawn at time intervals of $0.30,1,2,4,8,10,12,15$ min respectively and replaced the same with fresh dissolution medium to maintain a constant volume after each sampling. The withdrawn samples were filtered through Whatman filter paper and were analysed spectro-photometrically at $279 \mathrm{~nm}$ using UV-visible spectro-phometer.

\section{Ex vivo permeation study ${ }^{9,10}$}

Ex vivo permeation studies were carried out using porcine mucosa using modified Franz diffusion cell. The diffusion cell consists of donor compartment and receptor compartment, water jacket and sampling port. The receptor compartment of diffusion cell was filled with phosphate buffer $\mathrm{pH} 6.8$ (40 ml). Small magnetic bead was placed in the receptor compartment for agitating the buffer solution. Porcine oral mucosa was used as the model membrane. The mucosa was mounted between the donor \& receptor compartments. Formulated optimized film having dimension $2 \times 2 \mathrm{~cm}^{2}$ was placed over the porcine oral mucosal membrane. The donor compartment was then positioned and fixed over it with the help of clamps. The donor compartment was filled with $1 \mathrm{ml}$ of phosphate buffer of $\mathrm{pH}$ 6.8. The whole assembly was placed on a magnetic stirrer and the solution in the receptor compartment was continuously stirred. The temperature was maintained at $37 \pm 2^{\circ}$. Samples of $1 \mathrm{ml}$ were withdrawn at suitable time interval of $2,4,6,8,10,15,20,30,40,50$ and 60 minutes and were analyzed at $279 \mathrm{~nm}$ spectro-photometrically by using UV-visible spectrophotome Results of ex vivo studies of optimized formulation F2 is shown in Figure 3.

\section{Stability study}

Stability studies are essential component allowing the evaluation of active pharmaceutical ingredient stability under the influence of a range of environmental factors such as temperature, humidity and light.

\section{Procedure}

Stability study was carried out at two different storage conditions.

Normal room conditions $25^{\circ} \pm 2^{\circ} / 60 \% \mathrm{RH} \pm 5 \%$ and Accelerated conditions $40^{\circ} \pm 2^{\circ} / 75 \% \pm 5 \% \mathrm{RH}$ for 60 days using stability chamber .Each piece of films of optimized formulation was packed in butter paper followed by aluminium foil. The films were evaluated for drug content, disintegration time and in vitro drug release after storage for 30 and 60 days. The values for in vitro release from the films were calculated and were compared for change in dissolution profile

\section{RESULTS}

\section{Evaluation Parameters of prepared fast dissolving oral films}

In the current study eight formulations of fast dissolving oral films of Orciprenaline Sulfate were formulated using HPMC E15 and HPMC E50 as film forming polymers. All the prepared films exhibited good physical appearance and homogeneity without any flaws or imperfections. The weight and thickness of all the films 
were found to be uniform showing that increase in polymer concentration increases the weight and thickness of the films. The results of weight and thickness were shown in Surface morphology of optimized patch is shown in Figure 5.

\section{Folding endurance}

The folding endurance of the film was found to increase with the increase in the concentration of polymer. The values of folding endurance for all the formulations were shown in Table 2.

\section{Surface $\mathrm{pH}$}

Surface $\mathrm{pH}$ of all the films were found to be close to the neutral $\mathrm{pH}$ indicating that there might be less probability that the films will cause an irritation to the oral mucosa thus promoting patient acceptance. The results were shown in Table 2.

\section{Swelling index}

The measurement of swelling index indicated that maximum swelling takes place in the formulations containing higher proportions of polymer HPMC E15 and HPMC E50. Swelling index affects the release of the drug. Higher the percentage of swelling less the drugs release.The swelling index of all the formulations was shown in Table 3.

\section{In vitro disintegration time}

All the formulations showed satisfactory disintegration time. The disintegration time for formulation F1 was the least whereas F8 showed maximum disintegration time. Evaluation of disintegration time showed that disintegration time increases with the increase in the polymer concentration. The results were shown in Table 3.

\section{Tensile Strength}

Tensile strength of all the formulation was in acceptable range conceding that the films had good flexibility and mechanical strength. The results were shown in Table 3.

\section{Percentage elongation}

Percentage elongation also contributes as an important parameter in deciding the physical strength and flexibility of the film. The formulation F4 showed highest elongation among all other films. The results were shown in Table 3.

\section{Drug content}

The drug content uniformity test was performed to ensure uniform distribution of drug. The results indicated that drug was uniformly distributed in all the formulations as shown in Table 3.

\section{In vitro Drug release studies}

The in vitro drug release profiles of all the eight formulations in $\mathrm{pH} 6.8$ phosphate buffer show differences in drug release based on their composition as given in Table 1. It was observed that all the prepared films showed more than $70 \%$ of drug release in 15 minutes. Study revealed that that drug release from the films containing HPMC E15 as the polymer was more as compared to those containing HPMC E50. The reason behind higher drug release may be due to the lower viscosity of the HPMC E15 polymer. Rapid drug dissolution was observed in formulations F1, F2, F3 and F5 which released 98.4, 96.7, 83.6 and 83.67 percent respectively, at the end of 15 minutes. The results are depicted in Table 3 and Figure 1 and 2. F1 formulation showed highest drug release of 98.4 percent than other formulations. Slow drug release was observed in F4, F6, F7 and F8 with release of 72.7, 76.9, 77.1 and 10.6 percent respectively, at the end of 15 minutes as shown in Table 3, Figure 1 and 2. From all the prepared formulations, formulation F2 showed acceptable results having good physical and mechanical properties with optimum percent drug content, lesser disintegration time and maximum in vitro drug release of 96.79 percent. Therefore formulation F2 containing lower concentration of HPMC E15 as polymer was considered to be optimized formulation and was chosen for further study. The ex vivo permeation study was carried out to check the permeability of the drug through the porcine oral mucosa. From the ex vivo study it was found that 93.9 percent of drug permeated through the porcine oral mucosa within 60 minutes from the optimized formulation F2. The optimized formulation also showed better drug release 77.1 percent when compared with the marketed formulation. The results were shown in Figure 4.

\section{Stability study}

Stability studies were performed on the optimized formulation F2 as per ICH guidelines for 60 days. Optimized formulation showed no major changes and revealed that the optimized formulation was stable both at normal and accelerated conditions.

\section{DISCUSSION}

Fast dissolving films of Orciprenaline Sulphate were prepared efficiently by employing solvent casting method. All the prepared films had smooth surface texture, were flexible and had superior physical and mechanical properties. The surface $\mathrm{pH}$ of all the formulations F1 to F8 was found to be neutral in the range of 6.47- 6.82 


\begin{tabular}{|c|c|c|c|c|c|c|c|c|}
\hline Table 1: The formulation used in preparation of Orciprenaline sulfate fast dissolving films \\
\hline Formulation Ingredients & \multicolumn{7}{|c|}{ Formulation code } \\
\cline { 2 - 9 } & F1 & F2 & F3 & F4 & F5 & F6 & F7 & F8 \\
\hline Orciprenaline Sulfate $(\mathrm{mg})$ & 10 & 10 & 10 & 10 & 10 & 10 & 10 & 10 \\
\hline HPMC E50 (\%w/v) & 1.5 & 2.5 & 3.5 & 4.5 & ----- & ------ & ----- & ----- \\
\hline HPMCE 50 (\%w/v) & ------ & ------ & ----- & ----- & 1.5 & 2.5 & 3.5 & 4.5 \\
\hline Propylene Glycol(\%v/w) & 10 & 10 & 10 & 10 & 10 & 10 & 10 & 10 \\
\hline Citric acid (\% w/v) & 0.5 & 0.5 & 0.5 & 0.5 & 0.5 & 0.5 & 0.5 & 0.5 \\
\hline Sodium Saccharine(\%v/v) & 0.25 & 0.25 & 0.25 & 0.25 & 0.25 & 0.25 & 0.25 & 0.25 \\
\hline Distilled water & q.s & q.s & q.s & q.s & q.s & q.s & q.s & q.s \\
\hline qs: quantity sufficient & & & & & & & &
\end{tabular}

\section{Table 2: Physicochemical properties of fast dissolving oral films of Orciprenaline sulfate}

\begin{tabular}{|c|c|c|c|c|}
\hline Formulation code & Weight $(\mathbf{m g})^{*}$ & Thickness $(\mathbf{m m})^{*}$ & Folding endurance $^{*}$ & ${\text { Surface } \mathbf{~ p H}^{*}}^{*}$ \\
\hline F1 & $58.3 \pm 0.05$ & $0.12 \pm 0$ & $253 \pm 2.64$ & $6.47 \pm 0.04$ \\
\hline F2 & $62.5 \pm 0.05$ & $0.156 \pm 0.05$ & $323 \pm 3.78$ & $6.56 \pm 0.02$ \\
\hline F3 & $64.2 \pm 0.10$ & $0.178 \pm 0.002$ & $380 \pm 1.52$ & $6.68 \pm 0.01$ \\
\hline F4 & $65.1 \pm 0.10$ & $0.216 \pm 0.005$ & $394 \pm 2.64$ & $6.82 \pm 0.01$ \\
\hline F5 & $47.6 \pm 0.05$ & $0.116 \pm 0.005$ & $323 \pm 4.02$ & $6.77 \pm 0.01$ \\
\hline F6 & $52.2 \pm 0.05$ & $0.183 \pm 0.11$ & $365 \pm 3.51$ & $6.73 \pm 0.01$ \\
\hline F7 & $55.1 \pm 0.15$ & $0.22 \pm 0.010$ & $385 \pm 1.5$ & $6.82 \pm 0.00$ \\
\hline F8 & $61.2 \pm 0.01$ & $0.25 \pm 0.011$ & $423 \pm 3.05$ & $6.75 \pm 0.01$ \\
\hline
\end{tabular}

Table 3: Evaluation parameters of fast dissolving oral films of Orciprenaline sulfate

\begin{tabular}{|c|c|c|c|c|c|c|}
\hline $\begin{array}{l}\text { Formulation } \\
\text { code }\end{array}$ & $\begin{array}{l}\text { Swelling } \\
\text { index* }\end{array}$ & $\begin{array}{c}\text { Disintegration time } \\
(\mathrm{sec})^{*}\end{array}$ & $\begin{array}{c}\text { Tensile strength* } \\
\left(\mathrm{g} / \mathrm{cm}^{2}\right)\end{array}$ & $\begin{array}{c}\text { Percentage } \\
\text { elongation* }(\%)\end{array}$ & $\begin{array}{c}\text { Drug content } \\
(\%)\end{array}$ & $\begin{array}{c}\text { Drug release } \\
(\%)\end{array}$ \\
\hline $\mathrm{F} 1$ & $0.041 \pm 0.0006$ & $16.04 \pm 0.06$ & $14.1 \pm 1.04$ & $10.4 \pm 0.115$ & $97.3 \pm 1.0 \%$ & 98.4 \\
\hline $\mathrm{F} 2$ & $0.056 \pm 0.003$ & $26.01 \pm 0.01$ & $47.7 \pm 1.10$ & $18.91 \pm 0.15$ & $97.9 \pm 0.4 \%$ & 96.79 \\
\hline F3 & $0.058 \pm 0.0030$ & $38.05 \pm 0.02$ & $55.5 \pm 1.32$ & $24.05 \pm 0.11$ & $96.3 \pm 0.7 \%$ & 83.62 \\
\hline F4 & $0.062 \pm 0.0029$ & $52.86 \pm 0.24$ & $76.1 \pm 1.75$ & $29.41 \pm 0.11$ & $94.5 \pm 1.2 \%$ & 72.77 \\
\hline F5 & $0.043 \pm 0.0032$ & $21.02 \pm 0.02$ & $17.0 \pm 2.00$ & $11.76 \pm 0.15$ & $95.8 \pm 0.4 \%$ & 83.67 \\
\hline F6 & $0.049 \pm 0.0019$ & $35.01 \pm 0.02$ & $38.6 \pm 2.08$ & $25 \pm 0.25$ & $96.7 \pm 0.9 \%$ & 76.95 \\
\hline $\mathrm{F} 7$ & $0.055 \pm 0.003$ & $57.05 \pm 0.03$ & $61.3 \pm 1.52$ & $21.05 \pm 0.15$ & $96.1 \pm 0.3 \%$ & 77.15 \\
\hline F8 & $0.065 \pm 0.0029$ & $60.1 \pm 0.02$ & $85.5 \pm 1.32$ & $27.71 \pm 0.11$ & $94.3 \pm 0.7 \%$ & 70.63 \\
\hline
\end{tabular}

concluding that films might not cause any potential irritation to the mucosa. All the films showed good disintegration time. Formulation F1 showed the least disintegration time compared to other films. The percentage drug content of all the formulations was found to be in the acceptable range of 94.3-97.9 percent. In vitro drug release study showed that all the films released more than 70 percent of drug within 15 minutes. From all the formulations F1 containing HPMC E15 as the film forming polymer showed the highest and the best drug release of 98.4 percent within $15 \mathrm{~m}$.

Formulation F2 was selected as the optimized formulation on the basis of drug content, percent CDR 96.79 percent, Disintegration time and folding endurance.
The optimized formulation also showed better drug release when compared with the marketed formulation of Orciprenaline Sulphate. The ex vivo permeation study showed that 93.9 percent of drug permeated through the porcine mucosa within 60 minutes from the optimized formulation F2.

Stability study for two months revealed that the formulations were stable at room temperature as well as in the accelerated stability conditions. From the studies performed it can be concluded that the fast dissolving oral films of Orciprenaline Sulphate has potential in the growing market for its safe, efficient, effective treatment of asthma to offer a quick relief. 


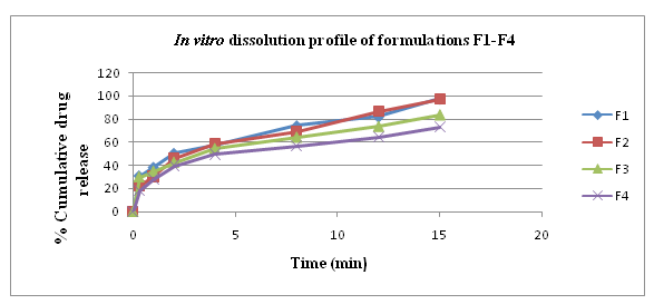

Figure 1: Illustration shows comparative in vitro dissolution profile of formulation F1-F4

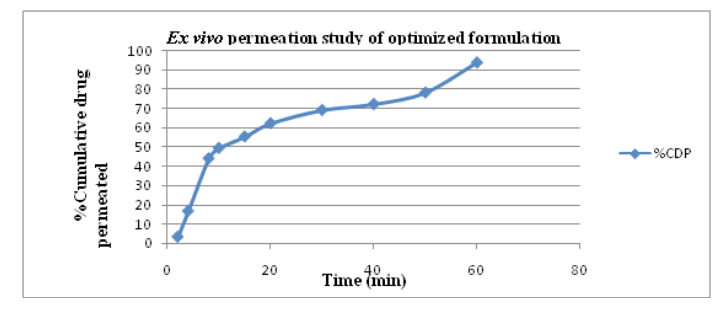

Figure 3: illustration shows ex vitro permeation study of optimized formulation F2

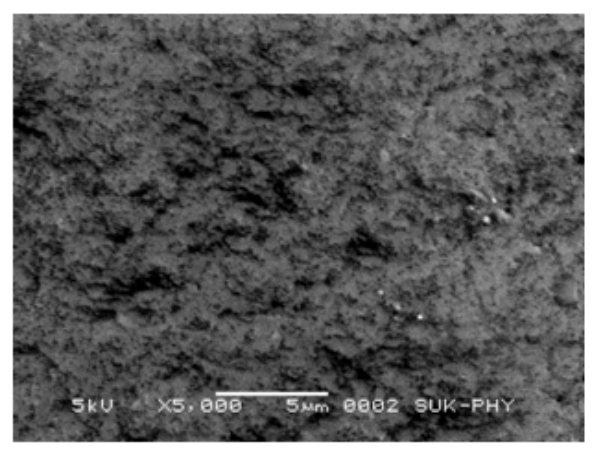

Figure 5: Illustration shows a SEM scanned image of optimized formulation F2.

\section{CONCLUSION}

Orciprenaline sulphate is bronchodilator which needs to release immediately allowing rapid distribution in blood. The results obtained after formulation oral fast dissolving films of Orciprenaline sulfate clearly indicate that it has improved bioavailability and rapid release rate. The formulation is tested for stability and the results are positive hence the formulation is stable.

\section{ACKNOWLEDGEMENT}

The authors would like to thank and appreciate Mrs. Medha Dessai, FDA Goa for helping them in procuring the drug as a gift sample for project work.

\section{CONFLICT OF INTEREST}

There are no conflict of interests.

\section{ABBREVATION USED}

Rpm: Rotations per minute; $\boldsymbol{\mu m}$ : Micrometer; \% Percentage; V/v: volume by volume; W/v: weight

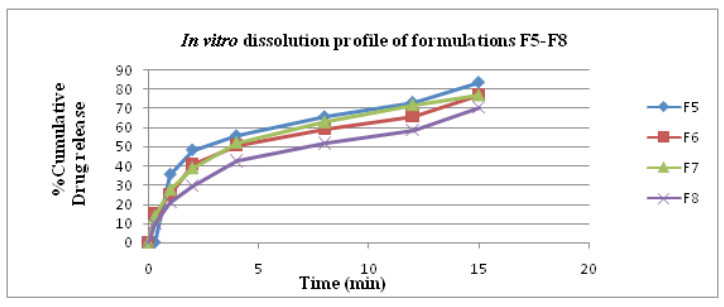

Figure 2: illustration shows comparative in vitro dissolution profile of formulation F5-F8

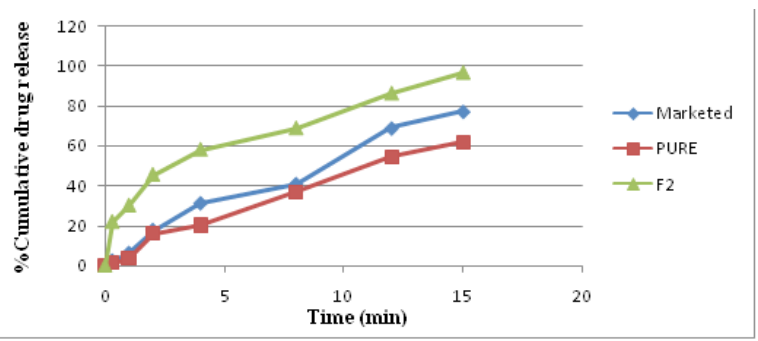

Figure 4: Illustration shows a comparison between in vitro drug-release of pure drug, optimized formulation F2 and marketed product.

by volume; W/w: weight by weight; FT-IR: Fourier Transform Infrared Spectroscopy; UV: Ultraviolet $\lambda_{\max }$ - Maximum Absorbance; DSC: Differential Scanning Colorimeter; RH: Relative humidity; \% CDP: Percentage Cumulative Drug Permeated; CLA: Cumulative loss added; PEG: Polyethylene Glycol; $\mathbf{R}^{2}$ : Regression coefficients; cP: Centipoises; HPMC: Hydroxy-PropylMethyl-Cellulose.

\section{REFERENCES}

1. Komargiri DS, Shaik F, Chandramouli Y, Vardhan VR, Amaravathi V, Uttardi A. Formulation And Characterization of Atenolol Fast Dissolving Films. IJPSR. 2012;2(2):58-62.

2. Orciprenaline Dose [internet] Available from http://www.drugsupdate.com

3. Patil PC, Shrivastava SK, Vaidehi S, Ashwini P. Oral Fast Dissolving Drug Delivery System: A Modern Approach for Patent Compliance. IJDRA. 2014;2(2):49-60.

4. Babitha TE, Umar F, Krishna RV, Krishna VM, Kumar SD. Development of Fast Dissolving Films of Timolol Maleate: Role of Hydrophilic Polymer. IJPRS. 2014;3(2):830-39.

5. Muzawar HM, Chandur VK, Shabaraya AR. Formulation Evaluation and Optimization of Fast Dissolving Oral Strips of Isosorbide Mononitrate. AJPTR. 2014;4(3):454-71.

6. Thakur N, Bansal M, Sharma N, Yadav G, Khare P. Overview "A novel Approach of Fast Dissolving Films and Their Patients" ABR. 2013;7(2):50-8.

7. Reddy P, Varma M, Betha S, Meecha R, Ratna VJ. Formulation development and characterization of Chlorpheniramine Maleate mouth dissolving film. Der Phaemacia Sinica. 2013; 4(5):1-9.

8. Desai P, Basu B. Design and evaluation of fast dissolving film of Domperidone, IRJP. 2012; 3(9):134-45.

9. Design and Evaluation of Buccal Patches of Granisetron Hydrochloride Swamy P.V.*, Amitkumar T., Shirsand S.B., Patil A. N. and Laeeq Farhana Department of Pharmaceutical Technology, HKE Society's College of Pharmacy Sedam Road, Gulbarga-585 105 (Karnataka-India) *For correspondence: E-mail: HYPERLINK "mailto:vspadavala@rediffmail. com"vspadavala@rediffmail.com

10. Optimization of Transmucosal Buccal Delivery of Losartan Potassium using Factorial Design Monica RP Rao1*, Swati Taktode1, Shivraj Sangappa 
Shivpuje1, Shilpa Jagtap1 1 Department of Pharmaceutics, AISSMS College of Pharmacy, Kennedy Road, Near R.T.O. Pune-411001, INDIA.

11. "In vitro and in vivo evaluation of chitosan buccal films of ondansetron hydrochloride" International Journal of Pharmaceutical Investigation, 2011;1(3):164-71.

12. Ilango R, Kavamani S, Mullaicharama AR,. Jaykar B. In vitro studies on buccal strips of glibenclamide using chitosan. Indian Journal of Pharmceutical Sciences 1997; 59(5): 2326

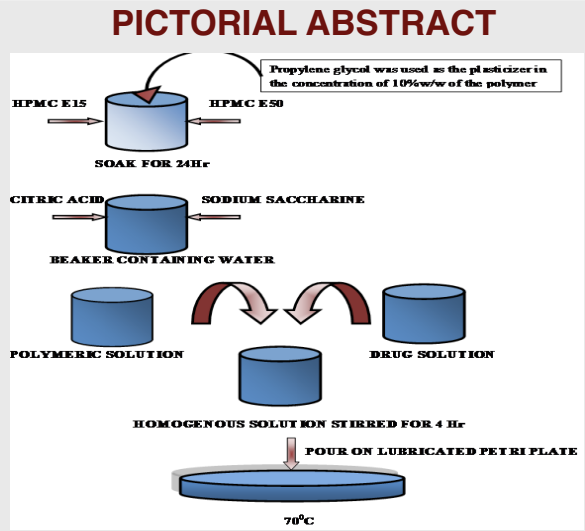

\section{About Authors}

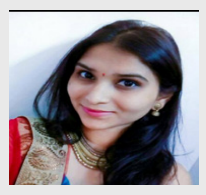

Saili Mahadev Prabhudessai: Obtained her post-graduate in 2016 from Dept. of Pharmaceutics, Faculty of Pharmacy, KLE University, Belagavi. She worked in the area Development and Characterization of Fast Dissolving Oral Films of Orciprenaline Sulphate.

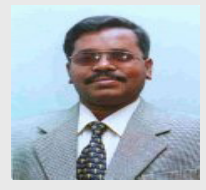

Panchaxari Mallappa Dandagi: Is a Professor, Department of Pharmaceutics, Faculty of Pharmacy, KLE University, Belagavi. He is working on areas of targeted drug delivery system viz., Colon drug delivery system using $\mathrm{pH}$ dependent polymers and also Ocular drug delivery system through Nano and microspheres.

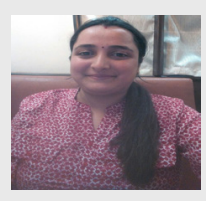

Yashaswini Lakshman: Obtained her post-graduate in 2017 from Dept. of Pharmaceutics, Faculty of Pharmacy, KLE University, Belagavi. She worked in the area of Melt sonocrystallized lornoxicam for oral delivery: particle characterization and solid state analysis.

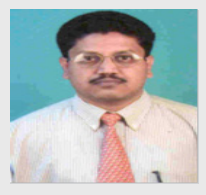

Anand Panchakshari Gadad: Is a Professor and Head, Department of Pharmaceutics, Faculty of Pharmacy, KLE University, Belagavi. $\mathrm{He}$ is working on areas of targeted drug delivery system viz., Gastroretentive drug delivery system, Polymeric nanoparticles, enhancing solubility of poorly soluble drugs, etc.
13. Gupta A, Garg S, Khar RK. Measurement of bioadhesive strength of mucoadhesive buccal tablets: design of an in vitro assembly. Indian drugs 1992; 30: 152-5. 12

14. Ahuja A, Dogra M, Agarwal SP. Development of buccal tablets of diltiazem hydrochloride. Indian Journal of Pharmaceutical Science 1995; 57 (1): 2630

15. Monica RP Rao, Priyanka Sadaphule. Development and Evaluation of Mucoadhesive Buccal Tablets of Ketorolac Tromethamine. Indian Journal of Pharmceutical Education and Research 2014;48(1):69-74.

\section{SUMMARY}

- Pre formulation studies were performed to examine the compatibility between drug and polymers. The IR spectra of the drug polymer mixture revealed that the results were found as given in the literature within prescribed limit, there was no interaction between the polymer and drug hence were found compatible.

- Fast dissolving films of Orciprenaline Sulfate were prepared efficiently by employing solvent casting method. All the prepared films had smooth surface texture, were flexible and had superior physical and mechanical properties.

- The surface pH of all the formulations F1 to F8 was found to be neutral in the range of 6.47- 6.82 concluding that films might not cause any potential irritation to the mucosa.

- All the films showed good disintegration time. Formulation F1 showed the least disintegration time compared to other films.

- The percentage drug content of all the formulations was found to be in the acceptable range of $94.3 \%$ $97.9 \%$

- In vitro drug release study showed that all the films released more than $70 \%$ of drug within 15 minutes. From all the formulations F1 containing HPMC E15 as the film forming polymer showed the highest and the best drug release of $98.4 \%$ within 15 minutes.

- Formulation F2 was selected as the optimized formulation on the basis of drug content, \%CDR $(96.79 \%)$, Disintegration time and folding endurance.

- $\quad$ The optimized formulation also showed better drug release when compared with the marketed formulation of Orciprenaline Sulfate.

- The ex vivo permeation study showed that $93.9 \%$ of drug permeated through the porcine mucosa within 60 min from the optimized formulation F2.

- Stability study for two months revealed that the formulations were stable at room temperature as well as in the accelerated stability conditions.

- From the studies performed it can be concluded that the fast dissolving oral films of Orciprenaline Sulfate has potential in the growing market for its safe, efficient, effective treatment of asthma to provide a quick relief

Cite this article: Saili PM, Dandagi PM, Yashaswini L and Gadad AP. Development and Characterization of Fast Dissolving Oral Films of Orciprenaline Sulphate. Indian J of Pharmaceutical Education and Research. 2017;51 (4):536-42. 